\title{
Recurrent ecological adaptations revealed through a molecular analysis of the secretive cophyline frogs of Madagascar
}

\author{
Franco Andreone ${ }^{\mathrm{a}, \mathrm{d}, *}$, Miguel Vences ${ }^{\mathrm{b}, \mathrm{d}}$, David R. Vieites ${ }^{\mathrm{b}, \mathrm{d}}$, Frank Glaw ${ }^{\mathrm{c}}$, Axel Meyer $^{\mathrm{d}}$ \\ ${ }^{a}$ Museo Regionale di Scienze Naturali, Via G. Giolitti, 36, 10123 Torino, Italy \\ ${ }^{\mathrm{b}}$ Institute of Biodiversity and Ecosystem Dynamics, Zoological Museum, Mauritskade 61, 1092 AD Amsterdam, The Netherlands \\ ${ }^{\mathrm{c}}$ Zoologische Staatssammlung, Münchhause 21, D-81247 München, Germany \\ ${ }^{\mathrm{d}}$ Lehrstuhl für Zoologie/Evolutionsbiologie, Department of Biology, University of Konstanz, 78457 Konstanz, Germany
}

Received 28 November 2003; revised 25 August 2004

Communicated by Adalgisa Caccone

\begin{abstract}
The cophyline microhylid frogs of Madagascar show a wide range of habitat specialization, ranging from terrestrial/burrowing and semi-arboreal to entirely arboreal species. The classification of these frogs is thus far mainly based upon morphological, largely osteological, characters that might be homoplastic. Using $1173 \mathrm{bp}$ of DNA sequences from the mitochondrial 12S and 16S rRNA genes, we here present a molecular phylogeny for 28 species of all known genera, except for the genus Madecassophryne. The resulting maximum likelihood tree contained four major clades: one represented by the genus Anodonthyla, the second by Cophyla and Platypelis, the third by several terrestrial and semi-arboreal species of the genus Plethodontohyla, and the fourth by species of the genera Stumpffia, Plethodontohyla, and Rhombophryne. The results confirm that several cophyline lineages adapted independently to similar habitats, with multiple shifts among terrestriality and arboreality. The direction of these shifts cannot be ascertained due to unclarified relationships among the most basal lineages, but for one terrestrial species (Anodonthyla montana), it is most parsimonious to assume that it evolved from arboreal ancestors. Our results suggest that the genus Plethodontohyla is probably paraphyletic, and that the classification of this and of the genus Rhombophryne needs to be re-assessed.
\end{abstract}

Keywords: Amphibia; Microhylidae; Cophylinae; Madagascar; 16S rDNA; 12S rDNA; Phylogeny

\section{Introduction}

Recent studies of the peculiar herpetofauna of Madagascar led to many surprising results. Several of the diverse vertebrate lineages of the "Grand'Ile" are monophyletic, and probably originated by ancestors that colonized the island from either Africa or Asia (e.g., Bossuyt and Milinkovitch, 2000; Yoder et al., 2003).

The only amphibians currently found on Madagascar are frogs-caecilians and salamanders are absent.

\footnotetext{
${ }^{*}$ Corresponding author. Fax: +39 0114323331.

E-mail address: f.andreone@libero.it (F. Andreone).
}

According to Vences and Glaw (2001) four frog families are currently recognized from Madagascar: the Mantellidae, Hyperoliidae, Ranidae, and Microhylidae. There are about 210 nominal frog species (Andreone and Luiselli, 2003), but many additional taxa still remain to be formally named and described (Glaw and Vences, 2000).

Malagasy frogs are adapted to a wide variety of habitats and are characterized by a high diversity of reproductive modes (Blommers-Schlösser and Blanc, 1991; Glaw and Vences, 1994). While considerable efforts have been directed towards the understanding of the taxonomy and phylogeny of the largest endemic radiation, the Mantellidae (e.g., Vences et al., 2003b), the microhylids 


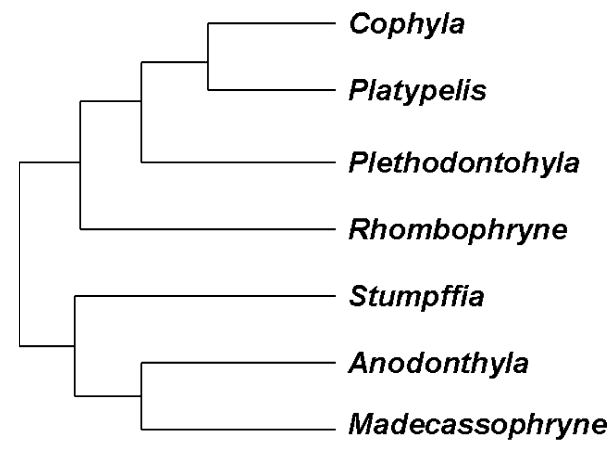

Fig. 1. Phylogenetic hypothesis of relationships among cophyline genera from Blommers-Schlösser and Blanc (1993). This tree was based on manual analysis of nine morphological and osteological characters.

remain one of the most enigmatic groups with unclear phylogenetic relationships. Of the three Madagascan subfamilies of the Microhylidae (Dyscophinae, Scaphiophryninae, and Cophylinae), the cophylines account the highest number of species, and show the highest diversity of ecological life-styles (Andreone, 1999). Because many cophylines are very secretive and are only occasionally encountered, their species inventory is far from complete and their classification still constitutes a great challenge for batrachologists.

Arboreal and semi-arboreal cophylines have enlarged finger disks and lay their eggs either into water filled tree holes or phytotelms, whereas the terrestrial and fossorial species without enlarged finger disks lay their eggs in terrestrial foam or jelly nests. As far as is known, all cophylines provide parental care and have non-feeding tadpoles (Andreone, 1999; Blommers-Schlösser, 1975; Glaw and Vences, 1994; Guibé, 1952; Köhler et al., 1997). Besides osteology (Guibé, 1978; Parker, 1934), the previous hypotheses on the phylogeny and classification of cophylines (Fig. 1) were largely based on morphological characters that are rather general such as the body form and size, or might be adaptive, such as terminal disks on fingers in arboreal species.

Here, we present the first comprehensive molecular phylogeny of this lineage, based on mitochondrial DNA sequences of representatives of all cophyline genera except for Madecassophryne. We discuss the occurrence of parallel shifts between arboreal and terrestrial specializations, and the current classification, in light of the molecular trees obtained.

\section{Materials and methods}

\subsection{DNA extraction and sequencing}

DNA was extracted from muscle tissue samples preserved in $95 \%$ ethanol. We used three pairs of primers to amplify three fragments of the $12 \mathrm{~S}$ and $16 \mathrm{~S}$ rRNA genes (Palumbi et al., 1991; Vences et al., 2003a): 12SA-L (light chain; 5'-AAA CTG GGA TTA GAT ACC CCA CTA T-3') and 12SB-H (heavy chain; 5'-GAG GGT GAC GGG CGG TGT GT-3') of Palumbi et al. (1991); 16SL3 (light chain; 5'-AGC AAA GAH YWW ACC TCG TAC CTT TTG CAT-3') and 16SAH (heavy chain; 5'-ATG TTT TTG ATA AAC AGG CG-3'); and 16SA-L (light chain; 5'-CGC CTG TTT ATC AAA AAC AT-3') and 16SB-H (heavy chain; 5'-CCG GTC TGA ACT CAG ATC ACG T-3'). PCR conditions followed Vences et al. (2003a). PCR products were purified using QIAquick purification kits (Qiagen) and sequenced using an automatic DNA sequencer (ABI 3100). Sequences were deposited in GenBank (Table 1).

Sequences were aligned using the Clustal option in SEQUENCE NAVIGATOR (Applied Biosystems). All sections that could not be reliably aligned, including those with three or more gaps in one or more taxa, were fully excluded from the analysis. Further gapped positions were excluded as well. The alignment and details about excluded sites are available from the authors upon request.

\subsection{Origin of samples}

The specimens and samples of muscle tissue were collected during recent field surveys in various regions of Madagascar. The samples were either immediately taken in the field and stored in $95 \%$ ethanol, or were taken from preserved museum specimens. For museum acronyms and voucher numbers, see Table 1 . We analyzed a total of 35 specimens attributed to 28 species, belonging to five of the six cophyline genera: Anodonthyla, Platypelis, Plethodontohyla, Rhombophryne, and Stumpffia. It was not possible to include the rare genus Madecassophryne, for which ethanol preserved material was not available. Our study encompasses a large proportion of the species diversity of each of these five genera, but considering the poor taxonomic knowledge it is not possible to reliably state which proportion of the species in each genus were sampled.

\subsection{Phylogenetic analysis}

The phylogenetic analyses were carried out using PAUP*, version $4 \mathrm{~b} 10$ (Swofford, 2001). Prior to phylogenetic reconstruction, we explored which substitution model fits our sequence data the best. We applied a hierarchical likelihood method to test the goodness-of-fit of nested substitution models, using the program Modeltest (Posada and Crandall, 1998). A Tamura-Nei $(\operatorname{TrN}+\mathrm{I}+\mathrm{G})$ substitution model was selected as best fit for the combined data set $(-\ln L=10882.2021)$, with empirical base frequencies (freq $\mathrm{A}=0.3816$; freq $\mathrm{C}=0.2552 ;$ freq $\mathrm{G}=0.1460 ;$ and freq $\mathrm{T}=0.2172$ ) and substitution rates $(\mathrm{A}-\mathrm{G}=3.8600 ; \mathrm{C}-\mathrm{T}=8.7935$; all 
Table 1

List of specimens used for analysis, and of GenBank accession numbers for the sequenced 12S, 16S-A, and 16S-B fragments

\begin{tabular}{|c|c|c|c|c|c|}
\hline \multirow[t]{2}{*}{ Species } & \multirow[t]{2}{*}{ Locality } & \multirow[t]{2}{*}{ Voucher } & \multicolumn{3}{|l|}{ Accession Nos. } \\
\hline & & & $16 \mathrm{~S}, 3^{\prime}$ fragment & $16 \mathrm{~S}, 5^{\prime}$ fragment & $12 \mathrm{~S}$ \\
\hline Anodonthyla boulengeri & Foulpointe & ZSM 264/2002 & AY 594091 & AY594053 & AY594015 \\
\hline Anodonthyla montana & Andringitra & UADBA-MV 2001.530 & AY 594090 & AY594052 & AY594014 \\
\hline Anodonthyla sp. 1 & Ranomafana & ZSM 673/2003 & AY 594092 & AY594054 & AY594016 \\
\hline Cophyla sp. 1 & Sahamalaza & ZSM 410/2000 & AY 594093 & AY594055 & AY 594017 \\
\hline Cophyla sp. 2 & Marojejy & MRSN A2660 & AY 594100 & AY594062 & AY594024 \\
\hline Platypelis barbouri & Andasibe & ZSM 1/2002 & AY 594098 & AY 594060 & AY 594022 \\
\hline Platypelis cf. barbouri a & Masoala, Andranobe & MRSN A2587 & AY 594094 & AY594056 & AY594018 \\
\hline Platypelis cf. barbouri b & Besariaka & MRSN A2616 & AY 594095 & AY594057 & AY594019 \\
\hline Platypelis cf. barbouri c & Tsararano & MRSN A1848 & AY594096 & AY594058 & AY594020 \\
\hline Platypelis grandis & Mantady & ZSM 162/2002 & AY 594102 & AY594064 & AY594026 \\
\hline Platypelis milloti & Manongarivo & ZSM 817/2003 & AY 594103 & AY 594065 & AY 594027 \\
\hline Platypelis sp. 1 & Ambolokopatrika & MRSN A2641 & AY 594097 & AY 594059 & AY 594021 \\
\hline Platypelis sp. 2 & Ranomafana & ZSM 791/2003 & AY594101 & AY594063 & AY594025 \\
\hline Platypelis sp. 3 & Tsaratanana & MRSN A2630 & AY594099 & AY594061 & AY594023 \\
\hline Plethodontohyla alluaudi a & Tsararano & MRSN A2620 & AY594105 & AY594067 & AY594029 \\
\hline Plethodontohyla alluaudi b & Masoala, Ilampy & MRSN A2584 & AY 594106 & AY594068 & AY594030 \\
\hline Plethodontohyla alluaudi c & Andasibe & ZSM 3/2002 & AY594112 & AY594074 & AY594036 \\
\hline Plethodontohyla brevipes & Ranomafana & ZSM uncatalogued & AY 594113 & AY594075 & AY594037 \\
\hline Plethodontohyla laevipes & Tsaratanana & MRSN A2631 & AY594107 & AY594069 & AY594031 \\
\hline Plethodontohyla coudreaui & Masoala & MRSN A2115 & AY 594110 & AY 594072 & AY 594034 \\
\hline Plethodontohyla inguinalis & Ranomafana & ZSM 666/2003 & AY 594118 & AY594080 & AY 594042 \\
\hline Plethodontohyla mihanika a & Masoala, Andranobe & MRSN A2645 & AY594116 & AY594078 & AY594040 \\
\hline Plethodontohyla mihanika $\mathrm{b}$ & Sandranantitra & MRSN A2652 & AY 594117 & AY594079 & AY594041 \\
\hline Plethodontohyla notosticta & Ambolokopatrika & MRSN A2650 & AY 594115 & AY594077 & AY594039 \\
\hline Plethodontohyla ocellata a & Masoala, Menamalona & MRSN A2589 & AY 594108 & AY594070 & AY594032 \\
\hline Plethodontohyla ocellata $\mathrm{b}$ & Masoala, Ilampy & MRSN A2665 & AY 594109 & AY594071 & AY594033 \\
\hline Plethodontohyla tuberata & Ankaratra & ZSM 375/2000 & AY594114 & AY594076 & AY594038 \\
\hline Plethodontohyla sp. 1 & Ambolokopatrika & MRSN A2640 & AY594104 & AY594066 & AY594028 \\
\hline Plethodontohyla sp. 2 & Ilampy & MRSN A2610 & AY594111 & AY594073 & AY594035 \\
\hline Rhombophryne testudo & Nosy Be & ZSM 475/2000 & AY594125 & AY594087 & AY594049 \\
\hline Stumpffia gimmeli & Antsirasira & MRSN A2633 & AY 594124 & AY594086 & AY594048 \\
\hline Stumpffia psologlossa & Nosy Be & Unlabeled & AY594122 & AY594084 & AY594046 \\
\hline Stumpffia pygmaea & Nosy Be & Unlabeled & AY 594123 & AY594085 & AY 594047 \\
\hline Stumpffia sp. 1 & Tsaratanana & MRSN A2653 & AY 594119 & AY594081 & AY 594043 \\
\hline Stumpffia sp. 2 & Ambolokopatrika & MRSN A2583 & AY 594120 & AY594082 & AY 594044 \\
\hline Stumpffia sp. 3 & Ambolokopatrika & MRSN A2651 & AY594121 & AY594083 & AY594045 \\
\hline Scaphiophryne boribory & Unknown & ZSM 153/2002 & AY 594126 & AY594088 & AY 594050 \\
\hline Scaphiophryne calcarata & Isalo & ZSM 118/2002 & AY 594127 & AY594089 & AY594051 \\
\hline
\end{tabular}

All localities are in Madagascar. Collection abbreviations as follows: MRSN, Museo Regionale di Scienze Naturali, Torino; UADBA, Université d'Antananarivo, Département de Biologie Animale; ZSM, Zoologische Staatssammlung, München.

other rates $=1$ ), a proportion of invariable sites of 0.3642 and a gamma distribution shape parameter of 0.6572 .

This substitution model was used to obtain maximum likelihood trees using the heuristic search option with tree-bisection reconnection (TBR) branch swapping, and a random sequence-addition sequence with 10 replicates. Additionally we carried out searches under the maximum parsimony optimality criterion, and random addition sequence with 1000 replicates. We calculated 2000 bootstrap replicates under maximum parsimony and 100 bootstrap replicates under maximum likelihood to test for the robustness of nodes. Bootstrapping was carried out using full heuristic searches with random addition sequence.

Bayesian posterior probabilities were calculated using MrBayes, version 2.01 (Huelsenbeck and Ronquist,
2001). A GTR substitution model with six rate frequencies was selected as the most similar model to the $\operatorname{Trn}+\mathrm{I}+\mathrm{G}$ substitution model (the latter model is not available in MrBayes). Two millions of generations were run, every tenth tree collected, and the number of initial generations needed before convergence on stable likelihood values was empirically estimated at 40,000; the "burn in" parameter was consequently set at 2\% (4000 out of 200,000 trees were excluded from analysis).

In all analyses, we used two species of Scaphiophryne (Microhylidae: Scaphiophryninae) as outgroups. This subfamily resulted to be the possibly most basal microhylid taxon in a recent analysis by van der Meijden et al. (2004).

A simplified consensus tree was drawn manually based on the preferred maximum likelihood tree by col- 
lapsing all nodes that received insufficient bootstrap support and considering all taxa with a similar general ecological lifestyle (arboreal vs. terrestrial) as one branch, respectively. Possible transitions between these modes were plotted on this tree by hand, and the most parsimonious alternatives retained.

Alternative topologies were evaluated by Shimodaira-Hasegawa tests (Shimodaira and Hasegawa, 1999) as implemented in PAUP*. To avoid any bias by a priori selections of alternatives, we followed the procedure proposed by Nagy et al. (2003) in which all possible rooted trees are compared for a reduced taxon set of seven taxa. This set included an outgroup (Scaphiophryne boribory), as well as those species of the relevant clades which had the shortest branches and therefore presumably fewest autapomorphies: Anodonthyla montana, Anodonthyla boulengeri, Platypelis grandis, Plethodontohyla tuberata, Plethodontohyla inguinalis, and Stumpffia sp. 2 were included to test for the alternative of monophyly of arboreal and terrestrial clades, and a second set of taxa
(A. montana, P. grandis, and P. tuberata, P. sp. 1, Rhombophryne testudo and Stumpffia sp. 2) was used to test for the alternative of monophyly of the genus Plethodontohyla.

\section{Results}

After exclusion of hyper-variable regions and gapped characters, the data set comprised 1173 nucleotides of which 626 were constant and 403 were parsimony-informative.

The tree resulting from a maximum likelihood search is shown in Fig. 2. Maximum parsimony searches recovered a single most parsimonious tree (2048 steps; consistency index 0.389 , retention index 0.530 ; not shown) which agreed in the general topology with the maximum likelihood tree, except for the arrangement of the most basal clades. Considering the support from bootstrapping and Bayesian analysis,

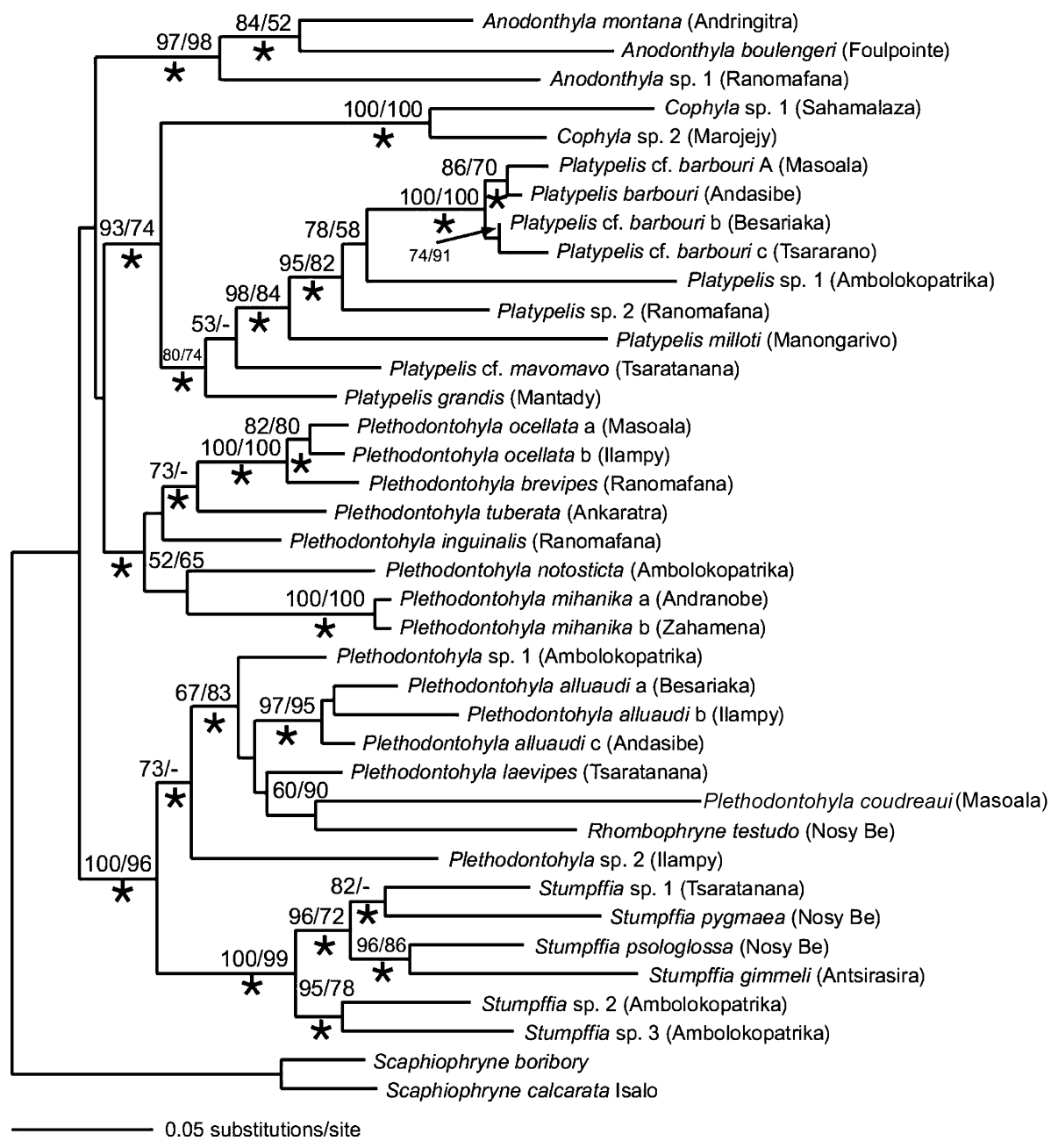

Fig. 2. Maximum likelihood tree, based on the analysis of 1173 nucleotides of the mitochondrial 12S and 16S rRNA genes. Numbers above branches are bootstrap values in percent for maximum likelihood (100 replicates) and maximum parsimony (2000 replicates). Values below 50\% are not shown. Asterisks indicate nodes that received clade credibility values of $98-100 \%$ in a Bayesian analysis. Two species of Scaphiophryne were used as the outgroup to root the tree. For accession numbers of the DNA sequences used, see Table 1. 
the basal splits among major cophyline lineages were not reliably resolved.

All the analyses agree in defining four major phylogenetic clades: (1) the Anodonthyla species; (2) a clade containing Cophyla and Platypelis, which formed well supported subclades, respectively; (3) a clade containing part of the species currently attributed to the genus Plethodontohyla (here named "Plethodontohyla group 1") and sister to Platypelis + Cophyla; and (4) a clade including the remaining Plethodontohyla species (here named "Plethodontohyla group 2") and R. testudo, and the species of Stumpffia. Rhombophryne is nested within this Plethodontohyla subset, and is sister to Plethodontohyla coudreaui.

Shimodaira-Hasegawa tests carried out on all possible topologies of a reduced set of seven taxa (see Section 2) indicated that all topologies that arranged either terrestrial or arboreal microhylids, or both, in monophyletic groups, had a significantly worse likelihood score than the preferred tree. On the contrary, the tests did not significantly exclude alternatives in which representatives of the two Plethodontohyla lineages were arranged into one monophyletic group.

\section{Discussion}

\subsection{Phylogenetic relationships and taxonomic implications}

The phylogeny presented herein provides novel information concerning the systematics of the Cophylinae. So far, cophylines were mainly classified based on osteological characters, mostly related to the configuration of the shoulder girdle and the skull (Blommers-Schlösser and Blanc, 1991; Guibé, 1978; Parker, 1934). BlommersSchlösser and Blanc (1993) presented a phylogenetic tree (reproduced in Fig. 1) that was based on nine characters of the external morphology (expanded terminal disks of fingers and toes) and osteology (successive reduction of vomerine and maxillary teeth). Other osteological characters, e.g., of the shoulder girdle, are useful to diagnose the different genera but no further synapomorphies of two or more genera have been identified so far (see BlommersSchlösser and Blanc, 1991, Blommers-Schlösser and Blanc, 1993). In this morphological tree, Anodonthyla (with Madecassophryne) was the sister group of Stumpffia, and Rhombophryne and Plethodontohyla successively split off a second major clade that led to the Platypelis/Cophyla lineage. The molecular data provide a rather different picture from the morphology-based phylogeny, Stumpffia apparently being related to a subgroup of Plethodontohyla and to Rhombophryne rather than to Anodonthyla, and Rhombophryne being nested within this Plethodontohyla subgroup. The molecular data here presented provide support for the monophyly of the genera Anodonthyla,
Platypelis, Cophyla, and Stumpffia. In contrast, the genus Plethodonthyla appears to be paraphyletic (" $P$. group 1 " + "P. group 2"), and Rhombophryne is closely related to and might be nested within "Plethodontohyla group 2."

The present phylogenetic reconstruction indicates that the two species here assigned to the genus Cophyla are genetically well differentiated from those assigned to Platypelis. This is remarkable, because the species belonging to these genera are very similar in their external morphology and natural history, and their identification in the field is very difficult. In fact, the main morphological character which allows to distinguish them are skeletal features: the absence of a clavicula and the fusion of the postchoanal parts of the prevomer in Cophyla (Blommers-Schlösser and Blanc, 1991, Blommers-Schlösser and Blanc, 1993).

The genus Plethodontohyla appears to be paraphyletic. The first clade, besides fossorial species (Plethodontohyla ocellata, Plethodontohyla brevipes, and $P$. tuberata), includes also the partly arboreal ones $(P$. inguinalis, Plethodontohyla mihanika, and Plethodontohyla notosticta). The molecular analysis grouped this lineage as sister group of Platypelis and Cophyla, but this grouping did not receive particularly strong bootstraps or Bayesian supports.

The second Plethodontohyla lineage, containing burrowing species only (e.g., Plethodontohyla alluaudi, Plethodontohyla laevipes), clusters with the genus Stumpffia which contains frogs that are also terrestrial but less secretive, and are often active during the day. Stumpffia contains many miniaturized species, with Stumpffia pygmaea being indeed one of the smallest frog species world wide and its juveniles, with snout-vent lengths of less than $3 \mathrm{~mm}$, holding the record for the smallest known (non-larval) tetrapods (Glaw and Vences, 1994).

Taxonomically, these molecular data indicate the possibility that the genus Plethodontohyla as currently understood might need a division into two separate genera. Of the available generic names, "Plethodontohyla group 1" contains the type species of Plethodontohyla $(P$. notosticta) and of its junior synonyms Phrynocara ( $P$. tuberata) and Mantipus (M. hildebrandti, junior synonym of $P$. inguinalis). The oldest available name for this lineage is therefore Plethodontohyla, and in the case of partitioning it therefore should be considered as Plethodontohyla sensu stricto. "Plethodontohyla group 2" apparently includes the type species (and only representative) of Rhombophryne, and therefore all species in this clade should be transferred to this genus.

However, as indicated by the Shimodaira-Hasegawa test, monophyly of Plethodontohyla cannot not be significantly rejected by our data. We therefore propose to postpone any taxonomic conclusion until a wider genetic data set, also including more species of Plethodontohyla, becomes available. No morphological or ecological syn- 
apomorphic characters to distinguish between the two Plethodontohyla groups are known.

Because no comprehensive phylogeny of the family Microhylidae (distributed in Africa, Madagascar, Asia, and the Americas) exists to date, the monophyly of the Cophylinae cannot be fully ascertained. However, it is conspicuous that as far as known the species assigned to this subfamily share a reproductive specialization with non-feeding tadpoles and parental care (BlommersSchlösser, 1975; Glaw and Vences, 1994) which is not found among other Malagasy microhylids. Almost all advertisement calls of cophylines consist of regularly repeated single notes of largely melodious structure (Glaw and Vences, 1994). Such a general call structure is not found in any other microhylid from Madagascar, and only in few mantellids (Mantidactylus eiselti, Mantidactylus enki, species of the Mantella cowani group). Vences et al. (2002) analyzed 16S rDNA sequences of one Anodonthyla, one Platypelis, one Stumpffia, and one Plethodontohyla together with sequences of scaphiophrynine, dyscophine, and microhyline species and found a strong support for a monophyletic clade containing the four included cophylines. A wider survey (M. Vences, unpublished data) that also included the African genera Breviceps, Phrynomantis, and Hoplophryne, as well as a broad sampling of Asian microhylids, recovered the included cophylines as monophyletic group as well. We therefore conclude that the Cophylinae are very likely to constitute a monophyletic endemic radiation of Madagascar.

\subsection{Ecological diversification, fossoriality, and arboreality}

The phylogenetic tree presented herein suggests that, within the Cophylinae, several evolutionary shifts occurred between arboreal and terrestrial adaptations. Fossoriality is seen as having evolved independently in numerous anuran families, and is thought to originate mainly in desert or semiarid conditions (Bragg, 1961; Garcia-París et al., 2003). Similarly, the typical morphological adaptations of treefrogs have evolved in parallel in several clades (e.g., Bossuyt and Milinkovitch, 2000). For cophylines, it is difficult to make statements about their ancestral life style, i.e., whether they were terrestrial or arboreal. Some Malagasy frog lineages are known to have colonized the island long after its separation from the African and Indian continents in the Cenozoic (Vences et al., 2003b), while others may have originated before the separation of Madagascar and India (Bossuyt and Milinkovitch, 2000; Vences et al., 2003b). Overseas dispersal in frogs seems to be especially likely in species with arboreal or semi-arboreal adaptations (Vences et al., 2003b), and certainly is more likely for arboreal cophylines that could survive in a tree hole on a rafting trunk, as compared to terrestrial or burrowing species.
On the other hand, if microhylids were present in Madagascar throughout the Mesozoic, it is more likely that they originally were adapted to seasonal and arid terrestrial environments, and later colonized the rainforests, secondarily evolving arboreal adaptations (Vences et al., 2002).

Because of the basal polytomy of major clades (Fig. 3 ), the molecular tree presented herein also does not unambiguously clarify the ancestral ecological/morphological adaptation of cophylines. However, as corroborated by the results of the Shimodaira-Hasegawa tests, monophyly of either the terrestrial or the arboreal lineages can be significantly excluded. From Fig. 3 it is clear that more than one shift from arboreality to terrestriality must have occurred within the subfamily. More detailed knowledge about the relationships among the four major lineages of cophylines is required before the direction of these transitions can be ascertained. What seems to be clear, however, is that in one case the direction of change was from arboreality to terrestriality: Anodonthyla montana is a montane species that lives above the tree line and that breeds in small rock pools (Blommers-Schlösser and Blanc, 1991), while all other Anodonthyla breed in tree holes or waterfilled cavities in bamboo (Blommers-Schlösser, 1975; Glaw and Vences, 1994). In our phylogenetic hypothesis (Fig. 2), A. montana is placed as the sister group of the arboreal $\mathrm{A}$. boulengeri, their clade being sister to another arboreal species (Anodonthyla sp. 1). Parsimony arguments therefore favour a scenario in which an arboreal ancestor of A. montana evolved terrestrial habits as adaptation to the high-altitude habitat, because the alternative would imply two independent transitions from terrestriality to arboreality (in $A$. boulengeri and $A$. sp. 1). This is indeed a trend shared by other amphibians and reptiles, which tend to become much more terrestrial at high altitudes. A similar tendency is known for the mantellid frogs of the genera Mantidactylus (e.g., Mantidactylus elegans) and Boophis (e.g., Boophis goudoti, Boophis microtympanum), and for lizards of the genus Phelsuma (P. barbouri) (Glaw and Vences, 1994).

Examples from other animal groups (e.g., Losos, 1992; Losos et al., 1998) suggest that recurrent evolution of similar ecomorphs may occur mainly under allopatric conditions. For cophylines it is relevant that the two major arboreal clades, Platypelis/Cophyla and Anodonthyla, clearly differ in their centers of diversity and endemism: While Anodonthyla occur in three endemic species in southeastern Madagascar and are absent from the north, most species of Platypelis occur in the north and Cophyla is endemic to this biogeographic domain (Glaw and Vences, 1994). Similarly, Stumpffia and "Plethodontohyla group 2" are mostly distributed in the north, whereas "Plethodontohyla group 1" is more widespread and contains several Plethodontohyla species known only from central eastern or eastern Madagascar: 


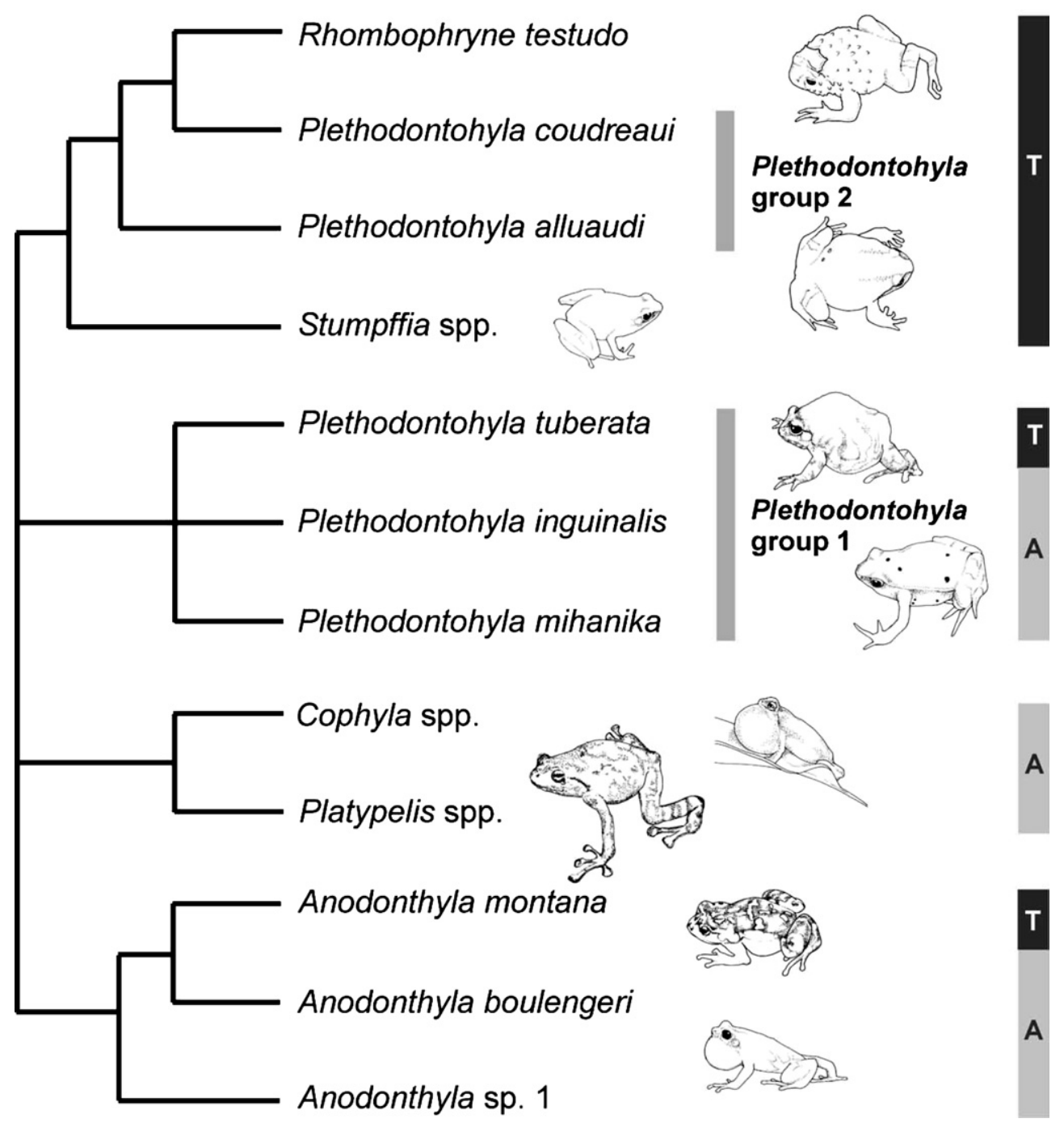

Fig. 3. Simplified phylogenetic tree of cophyline microhylids. Ecological preferences of the species are indicated with symbols: T and black vertical bars, terrestrial and fossorial species; A and gray vertical bars, arboreal and semi-arboreal species. The b/w silhouettes and the Latin names indicate representative cophyline species (or species groups) of each clade. The dark gray vertical lines indicate the two Plethodontohyla species groups.

P. tuberata, $P$. brevipes, and $P$. inguinalis. On a smaller scale, A. montana evolved adaptations to terrestrial habitats on Andringitra which is the only major Malagasy massif with no montane species of Plethodontohyla recorded from altitudes over $2000 \mathrm{~m}$ a.s.l. (Glaw and Vences, 1994).

Compared with scaphiophrynines (eight nominal species) and dyscophines (three nominal species), the Cophylinae are by far the most species-rich microhylid subfamily in Madagascar. It contains at least 38 nominal species, but many additional taxa have already been identified and await description (e.g., Andreone et al., 2003). Out of 28 taxa included in this study, 10 are likely as of yet undescribed species. A doubling of the cophyline species numbers seems not unrealistic according to our data. This remarkable species diversity is probably linked to the specialized reproductive mode of this lineage. Scaphiophrynines and dyscophines are generalized pond breeders, but due to the general topology, extended swamps and ponds are uncommon in Malagasy rainforests. Cophylines, in contrast, abandoned the free water bodies for reproduction, and can breed independently throughout the forest, as long as water filled cavities or sufficiently wet substrate is available. As a consequence, these frogs are almost completely absent from arid western Madagascar (Glaw and Vences, 1994) but are remarkably diverse in the eastern rainforests. The reproductive specialization of cophylines might have been the key innovation that allowed them to perform their species rich radiation into Malagasy forests, similar to the adaptation to lotic larval development in the brookbreeding clade of Boophis or the direct development in certain Mantidactylus (Andreone, 2003). Once they had become independent from open water bodies, the cophyline frogs therefore were able to radiate into new adaptive zones, and their novel evolutionary plasticity is 
reflected in the multiple shifts between arboreal and terrestrial specializations.

\section{Acknowledgments}

We are grateful to G. Aprea, F. Mattioli, L. Raharivololoniaina, H. Randriamahazo, J.E. Randrianirina, and D. Vallan for their help in the field. C. Girard drew the cophyline silhouettes. We are especially indebted to the Malagasy authorities for research and export permits. The work of F. Glaw and M. Vences was made possible by a cooperation accord between the Departement de Biologie Animale Antananarivo University and the Zoologische Staatssammlung München; that of $\mathrm{F}$. Andreone by a cooperation accord between the Parc de Tsimbazaza, Antananarivo, and the Museo Regionale di Scienze Naturali, Torino. This work was supported by grants of the Deutsche Forschungsgemeinschaft to M. Vences and A. Meyer, and of the Deutscher Akademischer Austauschdienst to F. Andreone and D.R. Vieites for their time in Konstanz, and D.R. Vieites by a grant of the University of Vigo for research in foreign countries.

\section{References}

Andreone, F., 1999. Madagascar amphibians. In: Yamagishi, S. (Ed.), "The Animals of Madagascar - its Wonderful Adaptive Radiation" [in Japanese]. Shokabo Publishing, Tokyo, pp. 213-261.

Andreone, F., 2003. The genus Mantidactylus. In: Goodman, S.M., Benstead, J.E. (Eds.), "The Natural History of Madagascar". Chicago University Press, Chicago, pp. 123-135.

Andreone, F., Fenolio, D., Walvoord, M.E., 2003. Two unknown arboreal frogs (genus Platypelis) described from the rainforests of northeastern Madagascar (Microhylidae: Cophylinae). Current Herpetology 22, 91-100.

Andreone, F., Luiselli, L., 2003. Conservation priorities and potential threats influencing the hyper-diverse amphibians of Madagascar. Ital. J. Zool. 70, 53-63.

Blommers-Schlösser, R.M.A., 1975. Observations on the larval development of some Malagasy frogs, with notes on their ecology and biology (Anura: Dyscophinae, Scaphiophryninae and Cophylinae). Beaufortia 24 (309), 7-26.

Blommers-Schlösser, R.M.A., Blanc, C.P., 1991. Amphibiens (première partie). Faune de Madagascar 75 (1), 1-379.

Blommers-Schlösser, R.M.A., Blanc, C.P., 1993. Amphibiens (deuxième partie). Faune de Madagascar 75 (2), 385-530.

Bossuyt, F., Milinkovitch, M.C., 2000. Convergent adaptive radiations in Madagascan and Asian ranid frogs reveal covariation between larval and adult traits. Proc. Natl. Acad. Sci. USA 97, 6585-6590.

Bragg, A.N., 1961. A theory of the origin of spade-footed toads deduced principally by a study of their habits. Animal Behav. 9, 178-186.

Garcìa-Parìs, M., Buchholtz, D.R., Parra-Olea, G., 2003. Phylogenetic relationships of Pelobatoidea re-examined using mtDNA. Mol. Phyl. Evol. 28 (1), 12-23.
Glaw, F., Vences, M., 1994. A Fieldguide to the Amphibians and Reptiles of Madagascar, Second ed., Including Mammals and Freshwater Fish. Vences and Glaw, Köln.

Glaw, F., Vences, M., 2000. Current counts of species diversity and endemism of Malagasy amphibians and reptiles. In: Lourenço, W.R., Goodman, S.M. (Eds.), "Diversité et Endémisme de Madagascar". Mémoires de la Société de Biogéographie, Paris, pp. 243 248.

Guibé, J., 1952. Recherches sur les batraciens de Madagascar. Mémoires de l'Institut scientifique de Madagascar (A) 7, 109-116.

Guibé, J., 1978. Les batraciens de Madagascar. Bonn. Zool. Monographien 11, 1-140.

Huelsenbeck, J.P., Ronquist, F., 2001. MrBayes: bayesian inference of phylogenetic trees. Bioinformatics 17, 754-755.

Köhler, J., Glaw, F., Vences, M., 1997. Notes on the reproduction of Rhombophryne testudo (Anura: Microhylidae) at Nosy Be, northern Madagascar. Rev. Fr. Aquariol. 24 (1-2), 53-54.

Losos, J.B., 1992. The evolution of convergent structure in Caribbean Anolis communities. Syst. Biol. 41 (4), 403-420.

Losos, J.B., Jackman, T.R., Larson, A., de Queiroz, K., RodríguezSchettino, L., 1998. Contingency and determinism in replicated adaptive radiations of island lizards. Science 279, 2115-2118.

Nagy, Z.T., Joger, U., Wink, M., Glaw, F., Vences, M., 2003. Multiple colonization of Madagascar and Socotra by colubrid snakes: evidence from nuclear and mitochondrial gene phylogenies. Proc. Roy. Soc. Lond. B 270, 2613-2621.

Palumbi, S.R., Martin, A., Romano, S., McMillan, W.O., Stice, L., Grabowski, G., 1991. The Simple Fool's Guide to PCR, Version 2.0. Privately published document compiled by S. Palumbi, Department of Zoology, University Hawaii, Honolulu.

Parker, H.W., 1934. A monograph of the frogs of the family Microhylidae. London: printed by the order of the trustees of the British Museum. Johnson reprint corporation, New York, pp. 207.

Posada, D., Crandall, K.A., 1998. Modeltest: testing the model of DNA substitution. Bioinformatics 14, 817-818.

Shimodaira, H., Hasegawa, M., 1999. Multiple comparison of log-likelihoods with applications to phylogenetic inference. Mol. Biol. Evol. 16, 1114-1116.

Swofford, D.L., 2001. PAUP*. Phylogenetic Analysis Using Parsimony (* and other methods), Version 4b8. Sinauer Associates, Sunderland, Massachusets.

van der Meijden, A., Vences, M., Meyer, A., 2004. Phylogenetic relationships of the enigmatic brevicipitine and scaphiophrynine toads as revealed by nuclear gene sequences. Proc. Roy. Soc. B (Suppl.) 271, S378-S381.

Vences, M., Aprea, G., Capriglione, T., Andreone, F., Odierna, G., 2002. Ancient tetraploidy and slow molecular evolution in Scaphiophryne: ecological correlates of speciation mode in Malagasy relict amphibians. Chrom. Res. 10, 127-136.

Vences, M., Glaw, F., 2001. When molecules claim for taxonomic change: new proposals on the classification of Old World treefrogs. Spixiana 24, 85-92.

Vences, M., Kosuch, J., Glaw, F., Böhme, W., Veith, M., 2003a. Molecular phylogeny of hyperoliid treefrogs: biogeographic origin of Malagasy and Seychellean taxa and re-analysis of familial paraphyly. J. Zool. Syst. Evol. Res. 41, 205-215.

Vences, M., Vieites, D.R., Glaw, F., Brinkmann, H., Kosuch, J., Veith, M., Meyer, A., 2003b. Multiple overseas dispersal in amphibians. Proc. Roy. Soc. Lond. B 270, 2435-2442.

Yoder, A.D., Burns, M.M., Zehr, S., Delefosse, T., Veron, G., Goodman, S.M., Flynn, J., 2003. Single origin of Malagasy Carnivora from an African ancestor. Nature 421, 734-737. 